\title{
Abordagem Indígena sobre Manejo Integrado do Fogo em Terras Indígenas no Estado do Tocantins - Brasil
}

\author{
Pedro Paulo Gomes da Silva Xerente ${ }^{1} \&$ Rejane Carneiro Salvador de Oliveira ${ }^{2}$
}

Recebido em 02/08/2020 - Aceito em 21/01/2021

\footnotetext{
1 Associação dos Brigadistas Xerente/ABX, Tocantínia/TO, Brasil. CEP: 77.640-000. <pedropauloxerente@gmail.com>.

2 Instituto Pedagógico de Desenvolvimento Agro-social e Comunitário/Inpac, Itaetê/BA, Brasil. CEP: 46.790-000. $<$ rejanecarneiro2000@yahoo.com.br>.
}

\begin{abstract}
RESUMO - O manejo integrado do fogo (MIF) pode ser uma abordagem nova para algumas pessoas e instituições públicas no Brasil, no entanto é prática comum nas comunidades das terras indígenas (TIs) Parque do Araguaia e Xerente, no estado do Tocantins. Estas manejam secularmente o fogo para reduzir o material combustível acumulado nas paisagens do Cerrado, garantir a frutificação das principais espécies nativas utilizadas em sua alimentação, caçar, confeccionar rota de fuga para os animais em caso de incêndios e para limpeza de roça e de áreas ao redor das aldeias. Unir esse conhecimento tradicional às diretrizes de atuação das instituições públicas representa um grande desafio no processo de construção do aprender a valorizar e respeitar o outro. Este seria o ponto de partida para construir estratégias que abarquem conhecimentos, técnicas e experiências almejando a harmonia entre os envolvidos, a preservação ambiental, a conservação dos patrimônios naturais e da biodiversidade existentes nas Terras Indígenas. $\mathrm{O}$ presente estudo traz a abordagem indígena sobre utilização do conhecimento tradicional sobre uso do fogo no âmbito do manejo integrado do fogo e do Programa de Brigadas Federais do Instituto Brasileiro do Meio Ambiente e dos Recursos Naturais Renováveis (Ibama), executado pelo Centro Nacional de Prevenção e Combate aos Incêndios Florestais (Prevfogo) nas TIs Parque do Araguaia e Xerente. O objetivo foi auxiliar a sociedade na compreensão do processo de integração entre instituição pública e comunidades indígenas na busca por melhorar a prevenção aos incêndios florestais e diminuir sua severidade nas terras indígenas.
\end{abstract}

Palavras-chave: Indígenas; manejo integrado do fogo; uso tradicional do fogo; Programa Brigadas Federais; terras indígenas.

\section{Indigenous Approach to Integrated Fire Management in Indigenous Lands in the State of Tocantins - Brazil}

\begin{abstract}
Integrated Fire Management can represent a new approach for some people and public institutions in Brazil. However, it is a common practice for indigenous communities of the indigenous lands Parque do Araguaia and Xerente, in the state of Tocantins. The communities use fire traditionally to reduce accumulated combustible material in the landscapes of Cerrado; to ensure fruiting and hunting; to build escape routes for animals in case of wildfires; to promote slashand-burn agriculture; and to clean the areas around the villages for protection. Bringing together traditional knowledge and institutional guidelines implies a challenge in the process of learning how to value and respect others. This is the milestone for developing strategies that encompass knowledge, techniques and experiences to achieve harmony among all stakeholders, and to promote conservation of natural heritage and biodiversity in indigenous lands. The present study addresses the indigenous approach of the use of fire according to the traditional knowledge within the scope of integrated fire management and the Federal Brigades Program of the Brazilian Institute for the Environment and Renewable Natural Resources (Ibama), carried out by the National Center for Prevention and Fighting Forest Fires (Prevfogo) in the indigenous lands Parque do Araguaia and Xerente. The objective was to assist society to understand the integration process between public institutions and indigenous communities in the search for improvements to prevent wildfires and to decrease their negative effects on indigenous lands.
\end{abstract}


Keywords: Indigenous peoples; integrated fire management; traditional use of fire; Federal Brigade Program.

\title{
Enfoque Indígena para el Manejo Integral del Fuego en Tierras Indígenas en el Estado de Tocantins - Brasil
}

\begin{abstract}
RESUMEN - El manejo integral del fuego puede representar un nuevo enfoque para algunas personas e instituciones públicas en Brasil. Sin embargo, es una práctica común para las comunidades de las tierras indígenas Parque do Araguaia y Xerente, en el estado de Tocantins. Las comunidades utilizan tradicionalmente el fuego para reducir el material combustible acumulado en los paisajes del Cerrado; para asegurar la fructificación y la caza; construir rutas de escape para animales en caso de incendios forestales; promover la agricultura de roza y quema; y limpiar las áreas alrededor de las aldeas para su protección. Unir conocimientos tradicionales y lineamientos institucionales implica un desafío en el proceso de aprender a valorar y respetar a los demás. Este es el punto de partida para desarrollar estrategias que abarquen conocimientos, técnicas y experiencias, con el objetivo de lograr la armonía entre todos los actores, la preservación y conservación del patrimonio natural y de la biodiversidad en tierras indígenas. El presente estudio aborda el enfoque indígena sobre el uso del fuego según el conocimiento tradicional en el ámbito del manejo integral del fuego y el Programa de Brigadas Federales del Instituto Brasileño de Medio Ambiente y Recursos Naturales Renovables (Ibama), realizado por el Centro Nacional de Prevención y Combate de Incendios Forestales (Prevfogo) en las tierras indígenas Parque do Araguaia y Xerente. El objetivo fue ayudar a la sociedad a comprender el proceso de integración entre las instituciones públicas y las comunidades indígenas en la búsqueda de mejorar la prevención a los incendios forestales y sus efectos negativos en las tierras indígenas.
\end{abstract}

Palabras clave: Pueblos indígenas; manejo integral del fuego; uso tradicional del fuego; programa de brigadas federales; tierras indígenas.

\section{Introdução}

O estado do Tocantins fica localizado na região norte do Brasil, encravado no bioma Cerrado. Neste estado existem quatorze terras indígenas (TIs), sendo que nove destas encontramse regularizadas (Funai, 2020).

As terras indígenas do estado do Tocantins, além da assistência da Fundação Nacional do Índio (Funai), a partir de 2013 começaram a ser atendidas pelo Instituto Brasileiro do Meio Ambiente e dos Recursos Naturais Renováveis (Ibama), com o Programa Brigadas Federais, executado pelo Centro Nacional de Prevenção e Combate aos Incêndios Florestais (Prevfogo), para apoio à preservação ambiental, prevenção, controle e combate aos incêndios florestais.

O fogo faz parte da cultura indígena desde seus ancestrais, sendo utilizado para cozimento dos alimentos, caça, limpeza de área para cultivo e proteção das moradias, entre outras utilidades. Ao longo do tempo as técnicas de uso do fogo foram sendo aprimoradas através das vivências e experiências empíricas e os indígenas aprenderam a manejar o fogo e a utilizá-lo também na prevenção aos incêndios florestais, a partir da redução do material combustível.

Com a implementação do Programa de Brigadas Federais do Prevfogo/Ibama nas terras indígenas do Tocantins surgiram divergências de opinião entre os técnicos do Prevfogo/ Ibama $e$ as lideranças indígenas. Houve defesa de posicionamentos de ambos os lados, tanto pelos servidores do Prevfogo/Ibama segundo sua doutrina de evitar o uso do fogo, quanto da Comunidade Indígena por ter a cultura em manejar com fogo a vegetação no período pós-chuva.

Depois das primeiras discussões, foi consenso a necessidade de reuniões para analisar a situação e a partir daí houve entendimento quanto ao uso do fogo para redução do combustível acumulado nas paisagens do Cerrado visando evitar a severidade dos incêndios na época crítica de sua ocorrência.

Nesse âmbito, o presente estudo teve como objetivo registrar a abordagem utilizada culturalmente para prevenção aos incêndios florestais realizada pelas comunidades indígenas nas TIs Parque do Araguaia e Xerente, no estado 
do Tocantins, e a integração desse conhecimento em práticas incorporadas pelo Programa de Brigadas Federais do Prevfogo/Ibama.

Para a realização deste estudo foram acompanhados os trabalhos do Prevfogo/Ibama durante quatro anos nas TIs, sendo registradas as observações de campo, do dia a dia nas aldeias, $e$ as discussões em reuniões para diagnóstico, planejamento e execução das práticas de manejo integrado do fogo (MIF) nas comunidades. Entende-se por MIF a integração da ciência e da sociedade com as tecnologias de manejo do fogo em múltiplos níveis. Pressupõe a compreensão da abordagem holística ou bem entrelaçada das questões do fogo, que leva em consideração as interações biológicas, ambientais, culturais, sociais, econômicas e políticas (Myers, 2006). Neste contexto a integração entre as técnicas de controle do fogo (prevenção, preparação, combate e uso do fogo) com os aspectos culturais, socioeconômicos e a ecologia do fogo tem como objetivo reduzir o número de incêndios (prevenção), aumentar a eficiência dos combates (preparação), melhorar o relacionamento entre os brigadistas e a comunidade (cultura do fogo) e garantir um regime de fogo adequado à preservação ambiental (ecologia do fogo). Uma vez que o fogo pode ser "bom" ou "mau", o fogo "bom" produz alimentos, ajuda na preservação da natureza e na proteção contra os incêndios florestais enquanto o fogo "mau" causa degradação ambiental e prejuízos às pessoas (Ibama, 2018).

Neste estudo foram definidas quatro perguntas norteadoras, de forma a construir sistematicamente a transcrição do olhar indígena sobre a utilização do conhecimento tradicional do uso do fogo $e$ a discussão entre as comunidades indígenas $e$ as instituições governamentais sobre o MIF.

Após quatro anos de acompanhamento da execução do Programa de Brigadas Federais e implementação do MIF nas TIs Parque do Araguaia e Xerente, por meio das observações, diálogos e registros feitos é possível afirmar que a integração entre instituição pública (Prevfogo/ Ibama) e comunidades indígenas conduzida com humildade e respeito aos conhecimentos de cada envolvido nesta relação é benéfica para ambas as partes e para o meio ambiente, no que concerne à preservação ambiental com a prevenção aos incêndios florestais e diminuição das ocorrências de incêndios severos.

\section{Material e Métodos \\ Área de abordagem}

Este estudo foi realizado nas terras indígenas Parque do Araguaia, que possui 1.358.499,48ha e tradicionalmente é ocupada pelas etnias Tapirapé, Javaé, Karajá e Ava Canoeiro, e na Terra Indígena Xerente, que possui 167.542,10ha e é ocupada pela etnia Xerente. Ambas se encontram regularizadas e totalizam uma área de $1.526 .041,58 \mathrm{ha}$, representando mais de $5 \%$ do território do estado do Tocantins (Figura 1).

A cobertura vegetal, uso e ocupação do solo da Terra Indígena Parque do Araguaia é caracterizada por $57,74 \%$ de formação natural não florestal; 38,74\% de floresta; 2,64\% agropecuária; $0,86 \%$ de corpos d'água e $0,02 \%$ área não vegetada. Já na Terra Indígena Xerente 95,94\% é floresta; $2,04 \%$ uso com agropecuária; $1,66 \%$ formação natural não florestal; $0,32 \%$ área não vegetada e 0,04\% corpos d'água (MapBiomas, 2020).

As TIs Parque do Araguaia e Xerente possuem Brigadas Federais Indígenas do Prevfogo/ Ibama, contratadas anualmente no período de junho a novembro no âmbito do Programa Brigadas Federais. Este Programa foi criado em 2013 com atuação nas terras indígenas por meio de Acordo de Cooperação Técnica celebrado entre Ibama e Funai, objetivando realizar ações de manejo integrado do fogo, que incluem a prevenção, monitoramento e combate aos incêndios florestais.

Por se tratar de brigadas federais em terras indígenas, estas são denominadas no Programa como "Brigadas Indígenas", e podem ser compostas exclusivamente por membros das comunidades indígenas ou complementadas com integrantes não indígenas, quando necessário (Ibama, 2018).

\section{Coleta de dados}

As informações foram coletadas a partir de observações de campo e conversas com brigadistas indígenas $e$ anciões (indígenas mais velhos) de maio de 2015 a setembro de 2019. Nesse período participaram dos diálogos aproximadamente quarenta anciões e sessenta brigadistas indígenas. 


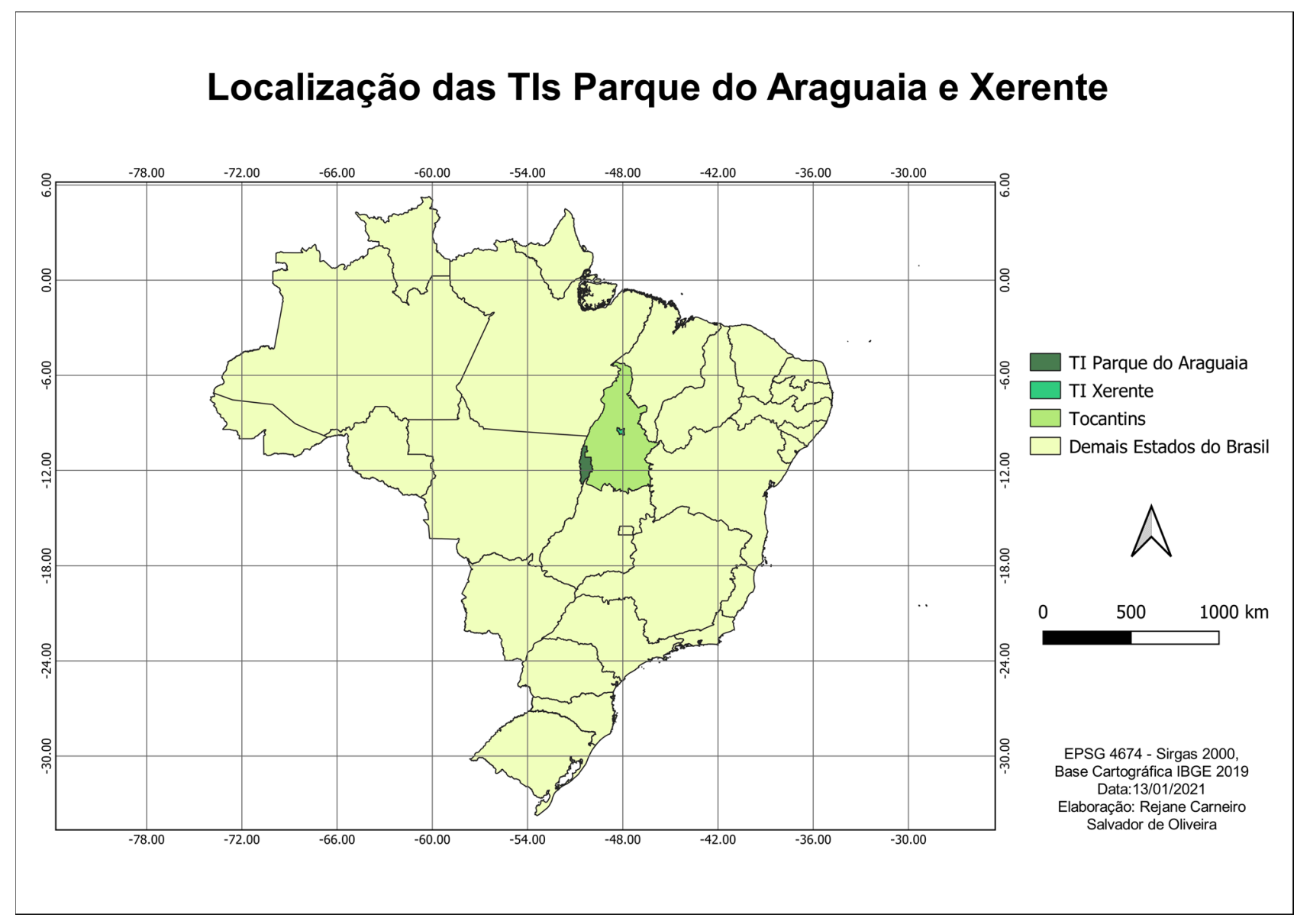

Figura 1 - Localização das TIs Parque do Araguaia e Xerente.

A coleta de dados foi feita de forma oral em rodas de conversa, seguindo ritual cultural indígena de transmissão de conhecimentos tradicionais. Este levantamento de informações foi facilitado pela participação de um indígena da TI Xerente, que participa das brigadas indígenas e possui boa articulação entre os povos Xerente, Ava-canoeiro, Javaé, Karajá e Tapirapé.

Objetivando transcrever o olhar indígena sobre a utilização do conhecimento tradicional do uso do fogo discutidos entre as comunidades indígenas $e$ as instituições governamentais $o$ presente estudo foi norteado pelas seguintes perguntas: Como as comunidades indígenas estão lidando com a abordagem do manejo integrado do fogo trazida pelo Prevfogo/lbama? Como os indígenas veem a utilização, pelas instituições, da sabedoria indígena para desenvolver o trabalho de prevenção, controle e combate aos incêndios florestais? Como as comunidades indígenas veem o trabalho das Brigadas Federais do Prevfogo/ Ibama? E como as comunidades indígenas veem a aplicação do seu conhecimento tradicional de uso do fogo frente às mudanças climáticas?

\section{Resultados}

\section{Como as comunidades indígenas estão lidando com a abordagem do manejo integrado do fogo trazida pelo Prevfogo/ Ibama?}

Para os indígenas das etnias Xerente, Ava-canoeiro, Javaé, Karajá e Tapirapé essa abordagem do manejo do fogo não é nova, o que há é a retomada do que se fazia antigamente, ou seja, o resgate do uso tradicional do fogo.

No início da execução do Programa de Brigadas Federais, durante o curso de Formação de Brigada promovido pelo Prevfogo/Ibama, os brigadistas eram instruídos a não deixar queimar. Todo fogo detectado deveria ser extinto (política de fogo zero). Essa postura provocou choque entre a cultura indígena e a estratégia adotada pela brigada. 
No entanto, esse conflito de posicionamentos foi conciliado através de reuniões entre servidores do Prevfogo/Ibama (técnicos e brigadistas) e anciões, (Figura 2), que passaram a orientar os brigadistas sobre a importância do uso do fogo na época pós-chuva e as técnicas utilizadas pelos seus ancestrais.

Por meio de diálogos e troca de experiências, os técnicos e brigadistas perceberam que a sabedoria tradicional de utilização do fogo no
Bioma Cerrado traria bons resultados para a conservação ambiental e passaram a incorporar essa cultura nas suas práticas a partir do ano de 2015, criando um marco histórico de participação, zelo pelo uso do fogo, trocas de conhecimento $e$ confiança entre as partes.

A partir desse momento percebeu-se uma satisfação dos indígenas em desenvolver o trabalho pensando na própria subsistência, pois a realização das queimas prescritas com a

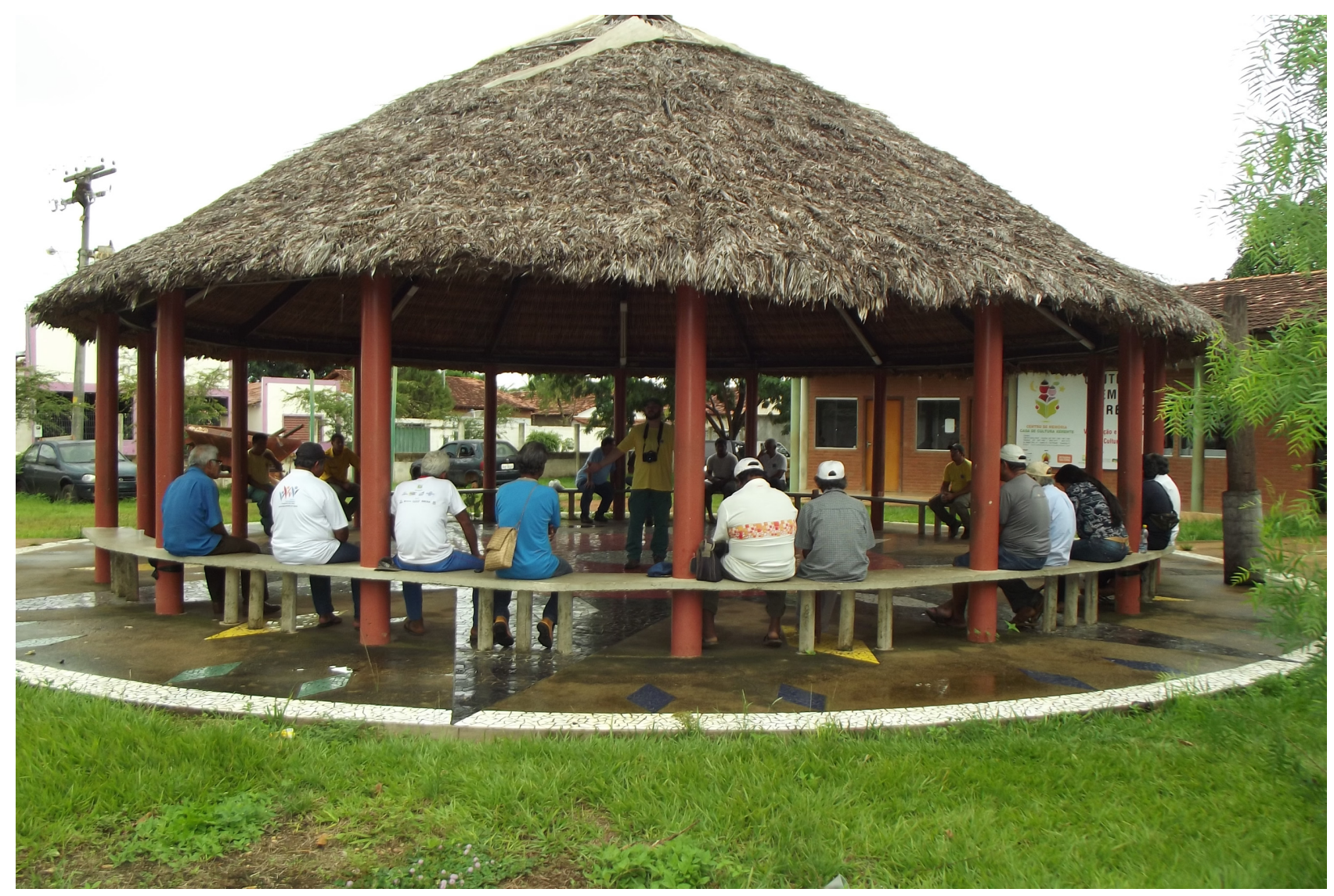

Figura 2 - Reunião entre servidores do Prevfogo/Ibama e anciões indígenas. Fonte: Acervo da Coordenação Estadual do Prevfogo/Ibama/TO.

integração do conhecimento técnico e cultura local, aumenta a produção de frutas e mantém a população faunística, garantindo assim alimento para comunidade.

Observou-se pelas falas que o manejo do fogo proporciona uma cadeia de resultados positivos, assim como a felicidade das comunidades indígenas por fazerem o que sabem, usando as estratégias que sempre utilizaram para sobreviver e usufruir de maneira sustentável dos recursos naturais do Cerrado.

\section{Como os indígenas veem a utilização, pelas instituições, da sabedoria indígena para desenvolver o trabalho de prevenção, controle e combate aos incêndios florestais?}

A comunidade indígena vê com satisfação e gratidão a utilização da sabedoria dos seus ancestrais por uma autarquia federal da magnitude do Ibama. Este, ao perceber que estava usando estratégias equivocadas, deu oportunidade à 
comunidade indígena para construírem juntos estratégias de manejo integrado do fogo, tanto na aplicação da educação ambiental, formação dos brigadistas, controle e combate aos incêndios florestais, quanto nas queimas prescritas. Nesse momento foi instituído pelo Prevfogo/Ibama um processo de construção coletiva, seguindo as orientações dos anciões, trocando experiências, ampliando as técnicas de queima e dando autonomia às brigadas indígenas para executarem o trabalho de acordo com a realidade local.

\section{Como as comunidades indígenas veem o trabalho das Brigadas Federais do Prevfogo/Ibama?}

A comunidade indígena vê com orgulho, mas também muita preocupação, considerando o grau de periculosidade que envolve a atividade de brigadista.

A comunidade apoia os brigadistas, os quais além de combaterem os incêndios florestais $e$ protegerem a biodiversidade das TIs, patrimônios natural e humano, desenvolvem também trabalho socioambiental, conseguem acessar todas as aldeias pela estrutura que o Prevfogo/Ibama oferece, orientam, plantam mudas de espécies frutíferas e arbóreas nativas, participam de eventos culturais, reuniões nas áreas de educação e de saúde. Enfim, a figura dos brigadistas na comunidade indígena é vista como elo entre os indígenas e o estado brasileiro.

\section{Como as comunidades indígenas veem a aplicação do seu conhecimento tradicional de uso do fogo frente às mudanças climáticas?}

Diante de um histórico de discriminação, preconceitos maldosos, difamações, perseguições entre outras situações difíceis, os indígenas se alegram por terem sido ouvidos e pelo uso tradicional do fogo estar trazendo benefícios ao meio ambiente.

$\mathrm{O}$ momento de aproximação, respeito $e$ humildade em saber ouvir $e$ aplicar os conhecimentos tradicionais demonstrado pelo Prevfogo/Ibama tem sido de muita alegria, não apenas pelo fato de serem reconhecidos ou respeitados, mas também por saberem que a Mãe Natureza terá dias melhores, que os guardiões estão contribuindo para que ela sofra menos e que a humanidade se beneficiará também.

Os indígenas sabem que ainda têm muito a contribuir para a conservação do meio ambiente, mas vivem, de certa forma, desprovidos de políticas públicas que garantam a todos os povos indígenas a permanência e proteção territorial. Enfrentam diariamente pressões no entorno de suas terras, pois estão vivendo em lugares ricos em épocas de crises financeiras. É notório que no Tocantins as terras indígenas figuram dentre os lugares mais preservados.

Ressaltam a importância do seu conhecimento tradicional para conservação ambiental, citam que não possuem certificados acadêmicos na área ambiental, mas possuem centenas de anos de experiências e práticas de como cuidar de quem os proporciona a vida. Vendo com muita gratidão a aplicação dos seus conhecimentos para reduzir as mudanças climáticas que a cada dia são mais severas.

\section{Discussão}

Em 2013, com o início do Programa Brigadas Federais a relação entre as comunidades indígenas $e$ as instituições governamentais foi conflituosa, uma vez que as brigadas indígenas quando contratadas eram orientadas a apagar todo e qualquer fogo, "política de fogo zero", não considerando que os indígenas ao longo dos séculos sempre fizeram uso tradicional do fogo com objetivos determinados pela comunidade como caça, limpeza ao redor das aldeias, garantia da frutificação, rota de fuga para fauna e manejo da flora. Estas queimas tradicionais eram realizadas ao final do período chuvoso para aproveitar a alta umidade da vegetação e realizar queimas de baixa intensidade, com segurança e que se extinguisse naturalmente.

Para reduzir os conflitos e conciliar o entendimento, o Prevfogo/Ibama promoveu encontros entre anciões, lideranças indígenas, brigadistas indígenas e técnicos do órgão a fim de discutir o uso do fogo e definir estratégias que atendessem aos interesses de ambas as partes. Só após esses encontros houve entendimento pelos técnicos do Prevfogo/Ibama da necessidade do uso do fogo pelos indígenas e que o fogo logo após o período chuvoso seria de baixo impacto. 
A partir deste entendimento os brigadistas contratados pelo Prevfogo/Ibama foram instruídos a acompanhar as queimas realizadas pelas comunidades com uso tradicional do fogo. A estas queimas as brigadas indígenas passaram a agregar conhecimentos técnicos como o uso de geoprocessamento e imagens de satélite na elaboração de mapas identificando os locais de acúmulo de biomassa.

Ao longo dos quatro anos de observações $e$ conversas com os anciões $e$ brigadistas verificou-se alguns pontos positivos em relação ao manejo integrado do fogo e da presença da Brigada Federal nas terras indígenas como o respeito pela pessoa índio e pelo conhecimento indígena, integração entre instituição pública $e$ comunidades indígenas, aproximação do Estado com as comunidades indígenas, criação de laços, compreensão da cultura indígena, oportunidade dos indígenas cuidarem da terra de forma remunerada, empoderamento e inclusão social, $e$ estabelecimento da brigada como elo entre comunidade e ações do Estado.

Na relação entre servidores do Prevfogo/ Ibama e comunidade indígena todo o processo de diálogo almejava objetivos em comum, utilizar a experiência dos anciões integrada a novas técnicas para aplicar o fogo nas épocas e locais predeterminados, manejar o material combustível, favorecer a frutificação, impedir a formação de grandes frentes de fogo e facilitar as ações de combate.

Nesse sentido, o bom andamento das atividades envolvendo o Estado $e$ a comunidade indígena está no desenvolvimento das ações de forma coletiva, dando aos envolvidos o direito $e$ liberdade de expressão e respeitando acima de tudo o posicionamento de cada indivíduo. Assim, os erros foram reduzidos e os laços de confiança fortalecidos. Consolidado esse entendimento, concluiu-se que o segredo estava não apenas em quem sabia mais, e sim na humildade de atuar juntos em busca do mesmo objetivo. Nunca trabalhar de forma paralela, pois isto gera atritos e problemas no resultado da ação.

\section{Conclusão}

O Estado e a comunidade indígena, com o desenvolvimento de ações harmônicas $e$ integradas, darão ao meio ambiente brasileiro mais proteção e segurança e, consequentemente as pessoas terão dias menos poluídos e mais gratificantes.

Os resultados positivos das ações desenvolvidas nas terras indígenas Parque do Araguaia e Xerente são visíveis. As comunidades indígenas estão sendo beneficiadas e tendo seus objetivos alcançados, a natureza está sendo preservada. Com as ações de manejo integrado do fogo as áreas manejadas estão produzindo mais frutos, fornecendo a matéria prima para os indígenas fazerem suas casas, tendo áreas incendiadas menores e menos impactos negativos na fauna e na flora. Como consequência, há melhora na qualidade de vida da comunidade indígena e fortalecimento das técnicas de gestão do uso do fogo nessas TIs.

Quanto aos pontos negativos em relação ao manejo integrado do fogo e à presença da Brigada Federal nas terras indígenas, identificase como ameaça a interrupção no processo de implementação do MIF, uma vez que as brigadas são contratadas anualmente apenas por seis meses, e nos outros seis meses do ano pode faltar estrutura (equipamentos e insumos) para as brigadas indígenas continuarem as práticas de manejo do fogo. Por fim, as mudanças de governo trazem insegurança e incerteza para continuidade do Programa de Brigadas Federais.

\section{Referências}

Funai (Fundação Nacional do Índio). 2015. Serviços ambientais: o papel das terras indígenas: Programa de Capacitação em Proteção Territorial. Diretoria de Proteção Territorial, Coordenação Geral de Monitoramento Territorial; FUNAI - GIZ (Orgs). Brasília. 179p.

Funai (Fundação Nacional do Índio). Terras Indígenas Parque do Araguaia e Xerente. Fundação Nacional do Índio. <http://www.funai.gov.br/index.php/indios-nobrasil/terras-indigenas > . Acesso em: 13/07/2020.

Ibama (Instituto Brasileiro do Meio Ambiente e dos Recursos Naturais Renováveis). 2018. Manual do Brigadista. 67p.

MapBiomas (Projeto de Mapeamento Anual da Cobertura e Uso do Solo no Brasil). Uso e cobertura do solo nas Terras Indígenas Parque do Araguaia e Xerente. Projeto de Mapeamento Anual da Cobertura e Uso do Solo no Brasil. < https://plataforma.mapbiomas.org/>. Acesso em: 30/10/2020. 
Myers RL. 2006. Convivendo com o Fogo - - Iniciativa Global para o Manejo do Fogo: Tallahassee, Manutenção dos Ecossistemas \& Subsistência com o USA. 36p.

Manejo Integrado do Fogo. The Nature Conservancy

Biodiversidade Brasileira - BioBrasil.

Edição Temática: 7th International Wildland Fire Conference

$$
\text { n. 2, } 2021
$$

http://www.icmbio.gov.br/revistaeletronica/index.php/BioBR

Biodiversidade Brasileira é uma publicação eletrônica científica do Instituto Chico Mendes de Conservação da Biodiversidade (ICMBio) que tem como objetivo fomentar a discussão e a disseminação de experiências em conservação e manejo, com foco em unidades de conservação $e$ espécies ameaçadas.

ISSN: 2236-2886 